10 InterAção

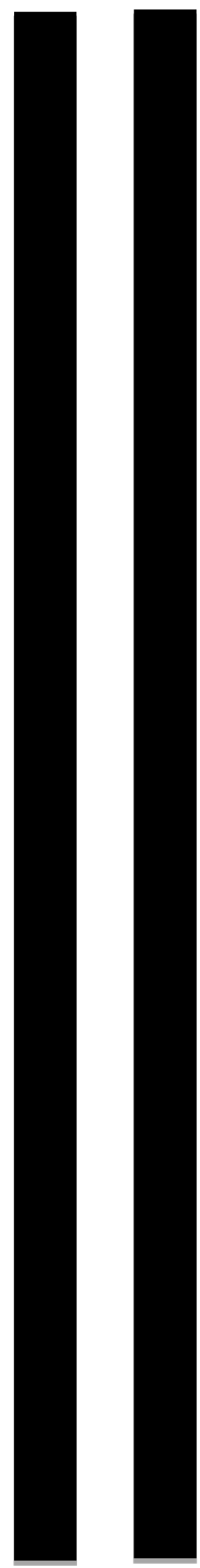

ARTIGOS 
11 InterAção

\title{
A PESCA COMO UM PROBLEMA DE SEGURANÇA: LIMITES E POSSIBILIDADES PARA A COOPERAÇÃO INTERNACIONAL NO OCEANO AUSTRAL
}

\author{
Luciano Vaz Ferreira ${ }^{1}$
}

\section{Resumo}

Com os estoques pesqueiros ao redor do mundo à beira do colapso, com consequências ambientais, econômicas e sociais imensuráveis, as possibilidades de proliferação da pesca INN (ilegal, não declarada ou não regulamentada) passaram a ser acompanhadas com grande atenção pela comunidade internacional. Neste contexto, desencadearam-se processos de securitização do problema. O Oceano Austral é particularmente vulnerável à pesca INN, podendo ser palco de novas dinâmicas de segurança. Neste contexto, apresenta-se o seguinte problema de pesquisa: "de que maneira ocorrem as dinâmicas de securitização do controle da pesca no Oceano Austral e qual o papel da cooperação internacional neste processo?". Além da resposta ao problema de pesquisa, que é o objetivo geral, o artigo possui como objetivos específicos investigar a securitização da pesca no cenário internacional, estudar as dinâmicas de segurança existentes no Oceano Austral, discutir os papeis da cooperação e dos regimes internacionais neste processo. A pesquisa é de natureza exploratória. Como técnica de pesquisa escolheu-se a revisão bibliográfica, servindo-se de material interdisciplinar e análise documental.

Palavras-chave: Segurança. Oceano Austral. Cooperação Internacional. Regimes Internacionais. Pesca.

\begin{abstract}
With fish stocks around the world on the verge of collapse, with immeasurable environmental, economic and social consequences, the possibilities for proliferation of IUU fishing (illegal, unreported or unregulated) have come under close scrutiny by the international community. In this context, processes of securitization of the problem were triggered. The Southern Ocean is particularly vulnerable to IUU fishing, and may be a stage for new security dynamics. In this context, the following research problem is presented: "In what way do the dynamics of securitization of fisheries control in the Southern Ocean occur and what is the role of international cooperation in this process?" Besides the answer to the research problem, which is the general objective, the article

\footnotetext{
1 Doutor em Estudos Estratégicos Internacionais (UFRGS), com período de pesquisa na American University (Washington, D.C.). Professor Adjunto do Curso de Relações Internacionais da Universidade Federal do Rio Grande. Direito do Mar (LABMAR).
} Membro do Instituto Brasileiro de Direito do Mar (IBDMAR). Pesquisador do Laboratório de Pesquisas em Política e
\end{abstract}


12 InterAção

aims to investigate the securitization of fishing in the international scenario, to study the security dynamics in the Southern Ocean, to discuss the roles of cooperation and international regimes in this process. The research is exploratory in nature. As a research technique the bibliographic review was chosen, using interdisciplinary material and documentary analysis.

Keywords: Security. Southern Ocean. International Cooperation. International Regimes. Fishing.

\section{INTRODUÇÃO}

Nas últimas décadas, é possível observar um aumento significativo do consumo de peixes e animais marinhos, que fazem parte da dieta diária de uma grande parte dos habitantes da terra, em diferentes sociedades. A crescente demanda, aliada aos avanços tecnológicos, produzem a elevação da captura destes animais, ameaçando a extinção de várias espécies e a destruição do equilíbrio dos ecossistemas marinhos. Seu habitat, os mares e os oceanos, constituem-se como espaços vastos em que a soberania dos Estados pouco alcança, tornando-os palcos de disputas internacionais. O Oceano Austral, que circunda o Continente Antártico, potencializa esta vulnerabilidade, por se tratar de lugar longínquo, que desperta cobiça por não estar ligado a nenhum Estado Costeiro e não ter a extensão de suas riquezas plenamente mensuradas.

Neste contexto, apresenta-se o seguinte problema de pesquisa: “de que maneira ocorrem as dinâmicas de securitização do controle da pesca no Oceano Austral e qual o papel da cooperação internacional neste processo?". Além da resposta ao problema de pesquisa, que é o objetivo geral, o artigo possui como objetivos específicos investigar a securitização da pesca no cenário internacional, estudar as dinâmicas de segurança existentes no Oceano Austral, bem como discutir os papeis da cooperação e dos regimes internacionais neste processo. A 
13 InterAção

pesquisa é de natureza exploratória, servindo como uma introdução à temática, ainda pouco discutida. Como técnica de pesquisa escolheu-se a revisão bibliográfica, servindo-se de material interdisciplinar (da área das Relações Internacionais e do Direito Internacional), e análise documental, com fontes retiradas de sites de organizações internacionais e governos.

$\mathrm{O}$ artigo divide-se em duas partes, a primeira de caráter geral e a outra de natureza específica. Na primeira parte discute-se o processo de securitização do controle da pesca internacional, sob o viés dos estudos estratégicos e de segurança. Ainda neste capítulo, analisa-se o papel desempenhado pela cooperação internacional e pelos regimes internacionais na segurança marítima. O foco principal será no regime da "Convenção das Nações Unidas sobre Direito do Mar" com especial ênfase nos dispositivos atinentes à pesca. Na segunda parte adentra-se ao estudo do Oceano Austral como um espaço de segurança, apresentando as principais dinâmicas existentes na região. Aqui, será discutida de que maneira ocorre a cooperação internacional no controle da pesca na região antártica, com especial ênfase nos esforços realizados no âmbito da "Convenção para a Conservação dos Recursos Vivos Marinhos Antárticos".

\section{A PESCA COMO UM PROBLEMA DE SEGURANÇA EA FORMAÇÃO DE REGIMES INTERNACIONAIS}

A pesca constitui-se como uma atividade humana de grande importância econômica e social. Atualmente, a venda de peixes e animais marinhos representa um comércio internacional avaliado em cerca de 153 bilhões de dólares em exportações (FAO, 2017). Um fato que chama a atenção é o aumento do consumo deste alimento nas últimas décadas. Enquanto na década de 60 capturava-se cerca de 20 milhões de toneladas por ano, estima-se em 2017 uma captura de 
$14 \mid$ InterAção

cerca de 90 milhões de toneladas (FAO, 2017). A média do consumo anual per capita na década de 60 era de 9,9 kg, enquanto em 2012, 19,2 kg, quase o dobro (FAO, 2014, p. 06). Dois fatores são apontados para esta elevação: primeiro, o desenvolvimento da tecnologia naval, que permite o deslocamento de frotas pesqueiras em longas distâncias e com a facilidade de captura em larga escala; segundo, a demanda mercadológica crescente por pescados, fruto do aumento populacional e a popularização do seu consumo, o que levou a ampliação da busca de estoques em todas as regiões do mundo para suprir esta procura (PAULY; ZELLER, 2016).

Esta expansão sem precedentes do mercado pesqueiro pode resultar em um colapso de todo setor, com consequências imprevisíveis. Em 1974, 90\% dos recursos pesqueiros eram explorados de maneira sustentável, ou seja, de modo a permitir a sua renovação natural. Em 2011, este índice foi mensurado em 68,6\%, o que significa que $31,4 \%$ de todos os estoques no mundo são objeto de sobrepesca, correndo o risco de serem extintos em um futuro próximo (FAO, 2016, p. 05-06).

Um elemento que contribui sobremaneira para esta dinâmica é a chamada “pesca ilegal, não declarada e não regulamentada - INN" (ilegal, unreported and unregulated fishing - IUU). Em linhas gerais, enquadram-se como "pesca ilegal" todas as atividades conduzidas contra regulações nacionais e internacionais; "pesca não declarada" é a realizada sem os devidos registros sobre a atividade (como a descrição e a quantidade do peixe, locais de pesca, uso de ferramentas de pesca); "pesca não regulada", por sua vez, é a perpetrada em locais ou circunstâncias onde não há regulação nacional ou internacional, como em algumas situações no alto-mar (PALMA et al, 2010, p. 38). Estima-se que 20 a $50 \%$ dos peixes são capturados ilegalmente, com rotulagem errada, sem registros ou de estoques sem qualquer programa de manejo sustentável. Esta prática ilícita é responsável por gerar de 15 a 36 bilhões de dólares anuais (FAO, 2016, p 05-06). 
15 InterAção

Nos últimos anos, a pesca INN tem sido classificada em alguns setores como um possível "problema de segurança". Um problema é "securitizado" quando apresentado como uma ameaça existencial a um objeto (geralmente um Estado, governo, território ou sociedade), requerendo medidas extraordinárias (BUZAN; WEAVER; WILDE, 1998, p. 23-24), que podem incluir o uso da força e resposta militar.

Tradicionalmente, a agenda de estudos estratégicos e de segurança envolvia somente a proteção do Estado ou governo contra ataques estrangeiros, em uma visão estadocêntrica (FIGUEIREDO, 2010, p. 273). Mais recentemente, no redimensionamento das relações internacionais a partir da Guerra Fria, uma nova abordagem propõe a ideia de "Segurança Humana" (Human Security), no qual os estudos de segurança deixam de ter foco exclusivo nos Estados para englobar também a sobrevivência e o bem estar dos indivíduos (PARIS, 2001, p. 88). Neste sentido, uma ameaça à segurança também pode ser definida como algo que possa degradar a qualidade de vida dos habitantes de um Estado de maneira rápida e drástica (ULLMAN, 1983, p. 129). É considerado como marco desta abordagem o estudo apresentado em 1994 pelo Programa das Nações Unidas para o Desenvolvimento, conhecido como Human Development Report 1994, que dedica um capítulo especial sobre o assunto, discorrendo sobre ameaças de segurança de natureza econômica, ambiental e social.

Estudos contemporâneos que abrangem a segurança humana têm optado em abordar a questão sob um ponto de vista construtivista, de maneira a observar como ocorrem os processos de securitização. Neste sentido, a definição de uma ameaça é vista como uma prática autorreferencial e socialmente constituída, não se baseando na real existência ou dimensão do problema, mas pela sua mera classificação por um "ato de fala” (BUZAN; WEAVER; WILDE, 1998, p. 24), realizado por um ator detentor de força política, e aceitação pela respectiva audiência (WEAVER, 1995, p. 56). 
16 | InterAção

Este discurso encontra-se consolidado em documentos oficiais de alguns governos dispondo sobre seus planos nacionais de segurança e estratégia marítima $^{2}$. Pioneiro entre as demais iniciativas, o documento sobre a estratégia norte-americana de segurança marítima de 2005 (National Strategy for Maritime Security) associa a exploração inadequada de recursos marinhos com danos ao meio ambiente e prejuízos à segurança econômica. $\mathrm{O}$ texto dispõe que a competição por estoques pesqueiros escassos pode resultar em conflitos violentos e instabilidade regional, necessitando que as marinhas nacionais tomem ações agressivas. Neste contexto, afirma que os "Estados Unidos e outras nações possuem interesses econômicos e de segurança substanciais em preservar a saúde e a capacidade produtiva dos oceanos". Conclui que os Estados Unidos irão continuar projetando a sua presença monitorando e patrulhando as águas que fazem parte da jurisdição norte-americana, assim como certas áreas do altomar onde há "interesse nacional". Mais recentemente, o National Intelligence Council, órgão de assessoramento do governo norte-americano em matéria de inteligência, publicou um relatório exclusivo sobre a temática da pesca INN (Global Implications of Ilegal, Unreported and Unregulated (IUU) Fishing, publicado em 2016), caracterizando-a como uma ameaça à segurança alimentar e econômica, além de beneficiar o crime organizado transnacional.

Este posicionamento não se limita apenas aos Estados Unidos. O documento sobre estratégia para segurança marítima do Reino Unido, de 2014, estabelece a necessidade de proteção contra ameaças oriundas de seu domínio marítimo, incluindo a exploração ilegal pesqueira. No texto, o Reino Unido coloca a pesca INN no mesmo patamar de outras ameaças, como o crime organizado e o terrorismo, o que demonstra a percepção de gravidade. Os

\footnotetext{
${ }^{2}$ A pesquisa pelos documentos disponíveis na internet foi feita por meio de acesso ao buscador google, lançando como palavras-chave "national maritime strategy" e "national maritime security". Na ocasião, em 26 de julho de 2018, foram encontrados os planos nacionais de estratégia marítima dispostos em língua inglesa dos Estados Unidos, Reino Unido, França, Espanha, Índia e União Europeia. Ficaram fora das pesquisas os planos não encontrados (possivelmente não disponibilizados na internet) ou apresentados em outra língua estrangeira diferente do inglês.
} 
17 InterAção

programas de segurança e estratégia marítima nacionais da Espanha de 2013, da Índia de 2015 e da França de 2015 seguem a mesma linha. A União Europeia lançou seu plano em 2014, classificando como ameaça à segurança marítima de seus Estados-membros os riscos ambientais, incluindo a pesca INN (Quadro 1).

Quadro 1. Referência ao problema da pesca nos documentos de segurança e estratégia marítima dos países e da União Europeia

\begin{tabular}{|c|c|c|c|}
\hline País & Nome do Documento & $\begin{array}{c}\text { Ano de } \\
\text { Publicação }\end{array}$ & $\begin{array}{c}\text { Número de referências às } \\
\text { palavras fish, fishing, } \\
\text { fishers } \text { ou fisheries }\end{array}$ \\
\hline $\begin{array}{c}\text { Estados } \\
\text { Unidos }\end{array}$ & National Strategy for Maritime Security & 2005 & 3 \\
\hline Espanha & National Maritime Security Strategy & 2013 & 14 \\
\hline Reino Unido & $\begin{array}{c}\text { UK National Strategy for Maritime } \\
\text { Security }\end{array}$ & 2014 & 64 \\
\hline Índia & $\begin{array}{c}\text { Ensuring Secure Seas: Indian Maritime } \\
\text { Security Strategy }\end{array}$ & 2015 & 62 \\
\hline França & $\begin{array}{c}\text { National Strategy for the Security of } \\
\text { Maritime Areas }\end{array}$ & 2015 & 14 \\
\hline $\begin{array}{c}\text { União } \\
\text { Europeia }\end{array}$ & $\begin{array}{c}\text { European Union Maritime Security } \\
\text { Strategy }\end{array}$ & 2014 & 67 \\
\hline
\end{tabular}

Quadro elaborado pelo autor, com base nos planos disponíveis na internet em língua inglesa (UNITED STATES, 2005; ESPAÑA, 2013; UNITED KINGDOM, 2014; INDIA, 2015; FRANCE, 2015; EUROPEAN UNION, 2014), consultados em 31 de julho de 2018.

Apesar de se tratar de um grupo de cinco países e uma organização internacional, devido à posição que ocupam no cenário mundial, é possível dizer que suas manifestações oficiais servem como uma espécie de "termômetro" de como uma parte importante da comunidade internacional de segurança tem tratado o tema recentemente. Tais discursos "securitizantes" do problema certamente encontram audiência e ressonância no cenário internacional.

Os planos nacionais de segurança e estratégia marítima consultados coadunam-se com a abordagem da segurança humana, classificando o problema da pesca INN como uma ameaça à segurança ambiental, econômica e alimentar, 
18 InterAção

três dimensões que se relacionam entre si. O Relatório Brundtland de 1987, produzido no âmbito da ONU e referência no desenvolvimento sustentável, classificou a proteção ambiental como pré-requisito para a sobrevivência da humanidade. A superexploração por recursos naturais, resultado de uma sociedade de consumo e crescimento desordenado, gera resultados irreversíveis ao meio ambiente, trazendo como consequência conflitos violentos e ameaças à existência e dignidade humana (MYERS, 1986, p. 251; MATTHEW, 2010, p. 08).

Diversas técnicas utilizadas na pesca INN são atentatórias à segurança ambiental, podendo acarretar extinção de espécies e danos irreparáveis à biodiversidade e à saúde dos ecossistemas (AGNEW, 2009). É comum o uso de práticas proibidas, como o cianeto, redes de arrasto no fundo de oceanos e explosivos (WWF, 2018). A pesca INN é a grande responsável pela captura acidental de animais marinhos que acabam não sobrevivendo, como espécimes jovens, tartarugas, golfinhos e aves oceânicas. Em alto-mar, é usual a utilização de redes fixas de grandes dimensões que são resgatadas pelas embarcações quando estão cheias, muitas acabam abandonadas, passando a capturar e matar animais indefinidamente. Uma prática corriqueira utilizada para burlar limites de quotas ou de locais autorizados para pesca é a transferência dos pescados para outras embarcações refrigeradas em alto mar, mascarando-se a origem do produto.

A segurança econômica relaciona-se à necessidade de assegurar renda básica à população, seja por meio do trabalho produtivo ou do sistema de seguridade social (UNDP, 1994). Estimativas apontam que entre 15 e $20 \%$ da população mundial adquire sua renda por meio da pesca (FAO, 2014), o que significa que a escassez de tal recurso pode colocar milhões de pessoas na pobreza estrema. 
19 InterAção

A segurança alimentar diz respeito ao acesso dos indivíduos à alimentação suficiente (UNDP, 1994). Observa-se que para 3,1 bilhões de pessoas no mundo o consumo de peixe representa cerca de $20 \%$ da proteína animal consumida diariamente (FAO, 2016, p. 04), constituindo-se como uma importante fonte de nutrição principalmente em países subdesenvolvidos e em desenvolvimento, nos quais esta média pode chegar a mais de 50\% (KAWARAZUKA; BÉNÉ, 2011). A diminuição drástica do estoque pesqueiro pode acarretar no agravamento da desnutrição nestes países.

Um argumento forte que tem sido utilizado no processo de securitização do controle da pesca INN refere-se aos seus laços com o crime organizado transnacional, fato apontado, inclusive, em manifestação da Assembleia Geral da ONU, em 2009 (A/RES/64/72). A vastidão do alto mar, a dificuldade de alcance de agências de aplicação do direito (law enforcement) e as baixas penas aplicadas para estes crimes tornam a atividade muito atrativa para esse tipo de organização (HAENLEIN, 2017, p. 08). Barcos que praticam pesca INN também são possivelmente utilizados para o transporte de drogas e armas, estando presentes nas principais rotas utilizadas por estas organizações. O trabalho análogo à escravidão também é comum, visto o tratamento comumente dispensado às tripulações destas embarcações (SHAVER; YOZELL, 2018, p. 16).

Caracterizada a pesca INN como um possível problema de segurança, a próxima discussão diz respeito às respostas oferecidas pelo sistema internacional (ou, pelo menos, as principais potências) para lidar com essa questão, que se desenvolve em um espaço de características muito peculiares: o mar. Historicamente, o mar sempre foi visto como uma zona de perigo e insegurança (MACK, 2011, p. 74), que serve não apenas como um corredor para a conexão entre os diferentes países (cerca de 90\% do comércio internacional é realizado pela via marítima), mas também como um palco de projeção de força, disputas militares e fonte de ameaças específicas (como a pirataria) (STEINBERG, 2001). 
20 InterAção

O ambiente físico marítimo é único e desafiador, devido a sua vastidão (70\% do planeta é coberto por água); inospitalidade (o ser humano é adaptado para viver na terra e não na água); e ausências de barreiras físicas que podem ser utilizadas como vantagem estratégica (inimigos podem se locomover em qualquer direção sem deixar rastros) (SPELLER, 2014, p. 16-18).

Os novos estudos sobre segurança marítima (surgidos na virada do séc. XXI) têm assumido que as particularidades do ambiente marinho exigem uma estratégia diferenciada, diversa do que vêm sido produzido no mainstream dos estudos estratégicos (BUEGER; EDMUNDS, 2017, p. 1296-1297). Enquanto nas ameaças ocorridas em terra firme são recorrentes o uso unilateral da força e o desapego pelo Direito Internacional, desenvolveu-se a ideia de que as ameaças marítimas necessitam de uma resposta baseada na cooperação internacional e no respeito às normas jurídicas internacionais.

Referente à cooperação internacional, observa-se que a manutenção da segurança marítima tem sido considerada pela política externa de diversos países como muito complexa e difusa para o controle de um único Estado, ainda que poderoso (BUEGER; EDMUNDS, 2017, p. 1297). A partir de 2005, a Marinha dos Estados Unidos passou a defender a posição de que os Estados Unidos eram incapazes de lidarem com os problemas de segurança marítima sozinhos, necessitando de uma estratégia de cooperação com outros Estados que compartilham os mesmos interesses, ideia que foi classificada como controversa à época.

O plano nacional de segurança marítima norte-americano define como uma das suas ações estratégicas "aumentar a cooperação internacional" em prevenir e responder às ameaças de origem marítima. Entre as iniciativas sugeridas, incluem a troca de informações entre órgãos de inteligência e law enforcement sobre atividades criminosas; a criação de banco de dados 
21 InterAção

internacional dispondo sobre registros de embarcações (incluindo dados sobre a tripulação e carga); oferecer ajuda econômica para outros países investirem em segurança marítima. Nos anos seguintes, a concepção de segurança marítima baseada na cooperação internacional acabou sendo reproduzida por uma série de planos estratégicos de países e organizações internacionais, que incluem o britânico (2014), francês (2014), australiano (2016) e da União Europeia (2014), da OTAN (2011), da União Africana (2014) e do G7 (2015) (BUEGER; EDMUNDS, 2017, p. 1298). Essa concepção enquadra-se no modelo de "marinhas pósmodernas" de Geoffrey Till (2014, p. 06-14), em que as marinhas e guardas costeiras nacionais, responsáveis por manter a ordem no ambiente marítimo, adotam uma postura colaborativa em relação aos seus congêneres, desenvolvendo atividades em conjunto para enfrentar atividades criminosas (TILL, 2016, p. 181).

O segundo aspecto caraterístico da segurança marítima refere-se ao papel importante que o Direito Internacional tem desempenhado nesta área. A razão está no desenvolvimento de um corpo jurídico próprio definindo regras detalhadas para a conduta e responsabilidades dos atores que atuam no espaço marítimo internacional, formando regimes internacionais especializados na área $^{3}$, que não encontra precedentes em outros temas securitários ${ }^{4}$. Neste contexto, o Direito Internacional aplicável à segurança marítima exerce a função de estabilizar as expectativas e dirimir os possíveis conflitos entre as potências navais, por meio do estímulo à cooperação internacional no enfrentamento de ameaças comuns (KRASKA; PEDROZO, 2013, p. 10). Direito e segurança marítima tornam-se temas indissociáveis, como pode ser constatado nas

\footnotetext{
${ }^{3}$ De acordo com Stephen D. Krasner (1982, p. 186) regimes internacionais são “princípios, normas, regras implícitos ou explícitos e procedimentos de tomadas de decisões de determinada área das relações internacionais em torno dos quais convergem as expectativas dos atores".
}

${ }^{4}$ Sobre o Direito Internacional da Guerra, ver Vaz Ferreira (2014). 
pesquisas de autores com foco exclusivo nas relações internacionais ${ }^{5}$ ou de abordagem interdisciplinar ${ }^{6}$.

Um dos instrumentos mais importantes é a "Convenção das Nações Unidas Sobre Direito do Mar" (United Nations Convention on the Law of the Sea UNCLOS) de 1982 (com vigor a partir de 1994). Amplamente aceita7, dispõe de temas variados como a conservação e exploração dos recursos marinhos e direito de navegação, regulações que impactam diretamente nas dinâmicas de segurança marítima ${ }^{8}$. Apesar de não terem ainda ratificado a Convenção, os Estados Unidos têm reconhecido suas cláusulas como normas costumeiras.

Em relação à pesca internacional e os limites na fiscalização de atividades ilícitas, a UNCLOS apresenta uma série de normas importantes. A pesca era considerada tradicionalmente pelo Direito Internacional como uma atividade livre e sem limitações, devido à crença de inesgotabilidade dos recursos (FULTON, 1911, p. 03). Algumas iniciativas foram desenvolvidas na primeira metade do séc. XX, destacando-se “Convenção Internacional para a Regulação da Pesca da Baleia" de 1946, constituída de uma organização internacional própria, até hoje em funcionamento.

A UNCLOS inova ao dividir entre os Estados dotados de litoral ("Estados Costeiros") o direito de explorar exclusivamente os recursos naturais, dentro de

\footnotetext{
${ }^{5}$ Autores que pesquisam o poder naval contemporâneo sob a ótica das relações internacionais e que são referências na área, como Geoffrey Till (2014) e lan Speller (2014) devotam espaço em suas pesquisas para discutir o papel do Direito Internacional, mais precisamente o regime da UNCLOS, nesta área.

6 É o caso das pesquisas de James Kraska (2011) e Natalie Klein (2011), ambos com formação jurídica e que pesquisam sobre segurança marítima.

${ }^{7}$ A UNCLOS encontra-se ratificada atualmente por 168 países e uma organização internacional (a União Europeia). Os Estados Unidos apesar de não terem ratificado a Convenção aceitam a sua aplicação como norma costumeira.

8 Um outro tratado que dispõe sobre questões de segurança marítima, mais precisamente sobre o terrorismo, é a "Convenção Internacional para Supressão de Atos llegais contra a Segurança da Navegação Marítima" de 1988, complementada por um protocolo sobre aplicação da convenção em plataformas fixas e outro sobre o uso de embarcações para o transporte de armas de destruição em massa.
} 
sua "zona econômica exclusiva" (ZEE), considerada como 200 milhas náuticas a contar da costa. A ideia é que ao definir "direitos de propriedade" (ou "direitos soberanos" de acordo com o texto do tratado) entre os Estados Costeiros sobre os estoques pesqueiros, colocando-os sob as suas jurisdições (embarcações nacionais e estrangeiras), haverá maior cuidado na sua exploração sustentável e fiscalização de atividades ilegais (art. 61 a 68 da UNCLOS) (ROTHWELL; STEPHENS, 2016).

Fora dos limites estabelecidos pelas ZEEs, adentra-se no alto-mar, onde a exploração continua, em princípio, livre para todos os países. Contudo, a UNCLOS estabelece um dever geral de conservação dos estoques no alto-mar, visto a natureza migratória dos animais marinhos e dos possíveis impactos negativos no ecossistema por conta da sobrepesca (art. 116 a 120 da UNCLOS). Neste caso, como se está falando de um espaço internacional, cabe ao Estado onde se encontra registrada a embarcação ("jurisdição da bandeira”) fiscalizar as suas atividades ilegais (art. 92), mantendo-se a prerrogativa de abordagem e inspeção ("direito de visita") (art. 110). No que tange à pesca, só é permitida a abordagem de embarcação estrangeira em alto-mar em três possibilidades excepcionais: a) perseguição contínua de embarcação que cometeu ato ilícito em ZEE nacional ("direito de perseguição") (art. 111); b) embarcações sem registro de nacionalidade (art. 110); c) embarcações de países vinculados a alguma organização regional de pesca (ratificada em instrumento pactício específico), que autorizam previamente fiscalizações mútuas ${ }^{9}$.

O desenvolvimento de regimes internacionais não acabou com a pesca INN, que continua a contribuir para a elevação de tensão entre diferentes países e impulsiona movimentos de securitização. O caso emblemático é do Mar do Sul

\footnotetext{
${ }^{9}$ É o caso, por exemplo, da "Comissão Internacional para a Conservação do Atum do Atlântico" (ICCAT); "Comissão para Conservação do Atum do Sul" (CCSBT); "Comissão de Pesca Ásia-Pacífico" (APFIC); "Comissão de Pesca e Aquicultura da Ásia Central e Cáucaso" (CACFISH); “Comissão de Pesca do Sudoeste do Oceano Índico”; “Comissão Internacional da Baleia" (IWC), entre outros.
} 
$24 \mid$ InterAção

da China que se converteu em um cenário de intensa disputa na delimitação da jurisdição dos Estados locais, dependentes da economia marítima (BECKMAN, 2013). Vários países da região têm coibido a ação das embarcações pesqueiras chinesas, que por vezes são acompanhadas por sua guarda costeira nacional. $\mathrm{Na}$ América Latina, é digno de nota a perseguição e o afundamento em 2016 de um barco chinês pesqueiro pela guarda costeira argentina, em uma medida que não era tomada em 15 anos (CNN, 2016).

\section{A COOPERAÇÃO INTERNACIONAL PARA O CONTROLE DA PESCA NO OCEANO AUSTRAL}

O Oceano Austral (ou Antártico) são as águas que circundam o Continente Antártico. Seus limites correspondem à chamada "Convergência Antártica", local onde as águas frias do polo sul encontram as águas mais quentes do sul dos Oceanos Atlântico, Pacífico e Índico ${ }^{10}$, formando um ecossistema marinho único. Apesar da existência do sétimo continente ser cogitada desde a Antiguidade, a exploração econômica dos recursos marinhos da região iniciou-se apenas no séc. XIX, a partir de uma série de incursões europeias buscando a captura de baleias, para a extração de óleo combustível, e focas, para o comércio de peles.

No séc. XX surge a exploração do krill antártico (euphausia superba), um pequeno crustáceo. Ele possui uma grande importância para a cadeia alimentar da região, ocupando sua base, pois serve de alimento primário para uma série de espécies, que incluem baleias, focas, pinguins, aves e peixes. O crustáceo é rico em proteína e possui baixa gordura. Além de ser apreciado como iguaria, tem

\footnotetext{
10 Existem divergências técnicas sobre a existência do Oceano Austral, se não seria apenas a junção das águas do Oceano Atlântico, Pacífico e Índico. Outra discussão seria em relação a sua delimitação, com a possibilidade de ser limitado no paralelo $60^{\circ}$, bem próximo ao Continente Antártico. Na presente pesquisa optou-se por utilizar a posição da Encyclopaedia Britannica e do CIA World Factbook, que identificam os limites do Oceano Austral com a Convergência Antártica.
} 
sido processado principalmente para servir como complemento alimentar para humanos, ração para peixes criados em cativeiro e iscas de pesca (ANTARCTIC AND SOUTHERN OCEAN COALITION, 2018). Além do krill, também são explorados comercialmente o bacalhau da Antártida (dissostichus mawsoni), a merluza-negra (dissostichus eleginoides) e o peixe gelo (champsocephalus gunnari).

A progressiva tomada de consciência do papel estratégico da Antártida e do Oceano Austral conduziram vários países a realizarem reivindicações territoriais ao longo do séc. $\mathrm{XX}$, no próprio Continente e ilhas adjacentes (subantárticas). Frente à ausência de população nativa, o objetivo principal era garantir a exploração exclusiva de seus recursos naturais. Com forte presença no extremo sul do Oceano Atlântico (dominando as ilhas de Falklands, South Georgia e South Sandwich), os britânicos realizaram suas reinvindicações em 1908, buscando garantir o monopólio da pesca da baleia (DODDS; HEMMINGS, 2012, p. 1436). Atualmente, as reinvindicações britânicas envolvem parte da Península Antártica (Graham Land), uma parte noroeste do Continente (Queen Elizabeth Land), além das Ilhas South Orkney e South Shetland. Posteriormente, o Império Britânico transferiu parte de seus domínios a suas ex-colônias: para a Nova Zelândia, as terras situadas no sul do Continente (em 1923) (Ross Dependency); para a Austrália, uma série de possessões no sudeste e nordeste do Continente $^{11}$ (em 1933), assim como as Ilhas Head e McDonald (em 1947).

A ação britânica estimulou a França a realizar sua própria reivindicação no Continente (Adélie Land, em 1924), contando com a facilidade de deslocamento por ocupar estrategicamente uma série de ilhas no Sul do Oceano Índico (Kerguelen, St. Paul e Amsterdam, Crozet e Scaterred Islands). A Noruega, por sua vez, também preocupada em explorar a pesca baleeira, anexou ao seu território a Ilha Bouvet (1927), situada no Atlântico Sul, próxima do Oceano

\footnotetext{
${ }^{11}$ Enderby Land, Kemp Land, Mac. Robertson Land, Princess Elizabeth Land, Kaiser Wilhelm II Land, Queen Mary Land, Wilkes Land, George V Land, Oates Land.
} 
Austral, a Ilha de Pedro I (1928) situada no Sudoeste e uma parcela do território norte do Continente (Terra da Rainha Maud, em 1939). Na década de 40, Chile (1940) e Argentina (1942), os dois países sul-americanos mais próximos fisicamente do Continente, realizaram suas reinvindicações. Neste contexto, originou-se uma situação conflituosa, visto que as reivindicações argentinas e chilenas sobrepunham-se em parte entre si e com a reivindicação britânica.

Durante a Guerra Fria os Estados Unidos intensificaram a sua presença na região, inclusive realizando manobras militares. A Operação High Jump, realizada entre 1946-47, contou com ampla participação das forças armadas (cerca de 4.700 soldados e 13 navios). Apesar de propagandeada como um mero exercício de treinamento possuía claros geopolíticos. É digno de nota o fato que os EUA não realizaram reivindicações territoriais. Uma manifestação oficial certamente desencadearia reação dos soviéticos, situação que, além de interferir na frágil estabilidade da região mantida pelos sete reivindicantes, exigiria dos EUA um emprego de força (política e econômica) que não dispunham na época, especialmente para uma região em que os ganhos econômicos e estratégicos ainda não eram muito claros (ABDEL-MOTAAL, 2016, p. 58-62).

Na iminência de uma disputa pela Antártida e seu Oceano, uma resposta cooperativa e multilateral ganhou força. Em 1957, criou-se um grande projeto internacional de pesquisa científica ("Ano Internacional da Geofísica”) que possuía como objetivo estudar com maior profundidade os fenômenos geofísicos da Terra, incluindo as dinâmicas existentes na Antártida. Surpreendentemente, os países que disputavam o Continente Antártico colocaram temporariamente suas pretensões de lado (incluindo os rivais EUA e URSS) e cooperaram neste projeto.

Como resultado desta aproximação inicial e da abertura do diálogo diplomático, em 1959, foi assinado o “Tratado da Antártida” (em vigor a partir 
27 InterAção

de 1961), com objetivo de mitigar as disputas internacionais em torno da questão $^{12}$. Sua área de abrangência são as terras e as águas abaixo do paralelo 60 S. O acordo fundamenta-se em três princípios básicos: a colaboração científica internacional deve ser encorajada, projeto que se concretizou com a instalação de várias unidades nacionais de pesquisa que compartilham a região antártica; a região deve ser uma zona de paz, excluindo-se atividades militares na área; as pretensões territoriais e discussões sobre soberania seriam suspensas enquanto na vigência do tratado.

Apesar de o Tratado da Antártida não dispor diretamente sobre o uso dos recursos marinhos, iniciativas posteriores lidaram diretamente com a questão, adotando um posicionamento pautado na exploração sustentável. Um primeiro acordo foi realizado em 1964, visando estabelecer a conservação e o uso racional da fauna e da flora ${ }^{13}$. Em 1972, promoveu-se um tratado sobre a conservação e regulação da caça da foca antártica $(\mathrm{CAS})^{14}$. Com o fim desta prática há décadas, o instrumento acabou tendo pouca aplicação. Em 1980, foi o ano da criação da “Convenção para a Conservação dos Recursos Vivos Marinhos Antárticos" (Convention on the Conservation of Antarctic Marine Living Resources - CCAMLR), entrando em vigor em 1982. A CCAMLR é aplicável a todos os recursos marinhos vivos da região, estabelecendo como princípio fundamental a salvaguarda do meio ambiente e a integridade do ecossistema antártico.

Em 1981 e 1987, os Estados Partes do Tratado da Antártida negociaram a criação de tratado internacional dispondo sobre a mineração na região, incluindo o uso dos fundos marinhos. Apesar da assinatura de uma Convenção, o projeto

\footnotetext{
12 Possui atualmente 53 Estados-Partes.

13 "Medidas Acordadas para a Conservação da Fauna e da Flora Antártica". 0 tratado acabou derrogado pelas iniciativas posteriores.

14 "Convenção para Conservação das Focas Antárticas" (Convention for the Conservation of Antarctic Seals - CAS), assinada em 1972, tendo entrado em vigor em 1978.
} 
acabou sendo abandonado, principalmente pela pressão do movimento ambientalista. Como reação, elaborou-se em 1991 o "Protocolo de Proteção Ambiental do Tratado da Antártida" ("Protocolo de Madrid"), em vigor em 1998. Entre as disposições do instrumento destacam-se a obrigatoriedade na realização de estudo e a avaliação de impacto ambiental em todas as atividades realizadas na região e a proibição de qualquer atividade de mineração até 2048, quando o instrumento será rediscutido.

O Tratado Antártico, a CAS, a CCAMLR e o Protocolo de Madrid fazem parte do "Sistema do Tratado da Antártida", um regime internacional especializado. Observa-se que a proteção da segurança ambiental é o principal elemento do regime antártico, visto que todas as discussões internacionais sobre as atividades presentes e futuras na região, ocorridas no âmbito desta estrutura, levam em consideração esta dimensão (ROTHWELL; SCOTT; HEMMINGS, 2012, p. 13-14). No que diz respeito à pesca, outros regimes de relevância são o do Direito do Mar (UNCLOS), que dispõe regras gerais sobre navegação e abordagem de embarcações e da "Convenção Internacional da Regulação da Pesca da Baleia", que por meio de sua organização internacional proibiu a atividade no Oceano Austral a partir de 1994, permitindo apenas em caso de pesquisa científica. As dinâmicas de segurança marítima, cooperação internacional e controle da pesca INN ocorridas no Oceano Austral submetemse a este framework jurídico.

Com a escassez dos estoques pesqueiros em diversas regiões do mundo, é natural o deslocamento destas atividades para outros mares em que ainda há abundância. Neste contexto, por se tratar de um local remoto e longe da fiscalização das jurisdições nacionais, o Oceano Austral apresenta-se vulnerável à exploração de seus recursos marinhos e, consequentemente, à pesca INN. Ainda que não tenha atingido níveis alarmantes, observa-se que nas últimas 
décadas a exploração de krill quase dobrou em quantidade ${ }^{15}$. As necessidades de segurança alimentar da China e dos países litorâneos do Oceano Índico (FOSTER, 2012, p. 166) também podem representar uma expansão em direção ao Oceano Austral em um futuro próximo. É digno de nota o fato que outros pescados da região possuem um grande valor de mercado atualmente, com pequenas cargas equivalendo a milhões de dólares, o que tem atraído o aumento da comercialização. O governo da Austrália já anunciou que considera a pesca INN na região antártica como sendo "uma forma altamente organizada de crime transnacional". Apesar de não existirem dados específicos sobre as atividades ilícitas (por se tratar de conduta realizada à margem da fiscalização) é plausível a sua ocorrência e intensificação. Como consequência, também se deslocam para a região as dinâmicas do processo de securitização do controle da pesca.

A CCAMLR tem sido o principal instrumento para coordenar a cooperação internacional no combate à pesca INN na região e na promoção da conservação do ecossistema marinho. O tratado criou uma organização internacional, mais precisamente uma "organização regional de pesca" (FABRA; CASCÓN, 2008, p. 573), com sede em Hobart, na Austrália. No que tange à adesão, além da participação dos sete reivindicantes originais, fazem parte da Convenção a União Europeia, EUA, China, Índia, África do Sul, Rússia, Japão, Bélgica, Brasil, Alemanha, Coreia do Sul, Namíbia, Polônia, Espanha, Itália, Suécia, Ucrânia e Uruguai.

A área de abrangência da CCAMLR é mais ampla que a do Tratado da Antártida, compreendendo todo o Oceano Austral. Isto significa que engloba tanto as águas abaixo do paralelo $60 \mathrm{~S}$, quanto aquelas que circundam ilhas subantárticas de soberania inconteste (britânicas, norueguesas, francesas, australianas, neozelandesas e sul-africanas). A razão de incluir as ZEEs destes

${ }^{15}$ Nos anos 90 anos 90 a média era de 100 mil toneladas ao ano, enquanto nos últimos anos têm ultrapassado 200 mil (CCAMLR, 2017). 
30 InterAção

países reside no fato que os recursos marinhos vivos certamente ignoram divisões políticas estabelecidas pelas relações internacionais, necessitando de monitoramento e proteção integral. Neste contexto, o regime da CCAMLR adota de maneira inovadora a "abordagem baseada em ecossistema": a diminuição do recurso marinho não deve ser individualmente considerada, mas a partir de uma análise do seu impacto no ecossistema e na cadeia alimentar (FABRA; GASCÓN, 2008, p. 567).

A partir das decisões da CCAMLR, são estabelecidas quotas anuais de pesca e áreas protegida. As ações da CCAMLR pautam-se no "princípio da precaução", que estabelece a proteção integral do recurso ambiental de um possível dano grave, ainda que haja incerteza científica sobre o tema (SANDS, 2003, p. 267-268). O objetivo é equilibrar entre a conservação e o uso racional dos recursos marinhos, de modo a consolidar uma pesca sustentável a longo prazo e minimizar os impactos no ecossistema local. As embarcações autorizadas para pesca pelos Estados-membros na região são registradas e monitoradas pela organização. Toda entrada ou saída deve ser comunicada à instituição, que divulga publicamente dados sobre o registro, histórico da pesca e equipamentos utilizados.

No que tange à pesca INN, os Estados ratificantes da CCAMLR são obrigados a reportarem qualquer atividade suspeita, de navios de sua bandeira ou origem estrangeira (incluindo de Estados que não fazem parte da Convenção). Como resultado, a organização publica uma "lista negra" com informações das embarcações avistadas, com nome, país de registro, possível dono e características. Os países de origem destas embarcações são notificados para que tomem providências cabíveis na investigação e punição destes atos (CCAMLR, 2018). 
31 InterAção

Apesar de apresentar um framework robusto e práticas consolidadas de cooperação internacional, o sistema da CCAMLR apresenta alguns gaps que podem constituir um desafio para a sua operacionalização. À exceção das ilhas subantárticas de soberania inconteste, que projetam jurisdição marítima em suas ZEEs, os mares que circundam a Antártida são considerados juridicamente como integrantes do alto-mar, com base na UNCLOS. Isto significa que os recursos marinhos dispostos nesta região são de livre exploração por qualquer país, seja ele integrante ou não do Tratado da Antártida ou da CCAMLR.

No que tange à fiscalização de pesca INN realizada pela CCAMLR, não se pode esquecer que a organização não possui uma força marinha própria, dependendo inteiramente da ação de seus membros. Neste contexto, a CCAMLR designa navios integrantes da marinha e da guarda costeira dos Estadosmembros para realizarem possíveis inspeções. Por conta do mandato do tratado, estas inspeções só podem ser realizadas em embarcações pesqueiras que possuem registro em países ratificantes da CCAMLR.

A utilização do modelo de "guarda-costeira", em que a força marítima possui treinamento adequado para abordagem e captura da embarcação e dos suspeitos em atividade pesqueira indevida, em contraste com treinamento militar para operações de guerra naval típico das marinhas tradicionais, parece ser o ideal para o contexto de segurança do Oceano Austral (BATEMAN, 2012, p. 130-131). Essa também é uma forma de mitigar um possível confronto com o Tratado da Antártida, visto que a função de law enforcement não seria, per si, uma atividade militar. Enquanto espaço naturalmente internacional, o Oceano Austral também é um lugar propício para testar a concepção de "marinha pós-moderna" de Till, baseada em ações colaborativas. Não se pode negar, contudo, que ampliação da presença de força marítimas, mecanismos de vigilância e infraestrutura de law enforcement, como reação à expansão da pesca INN, pode representar um elemento de tensão e conflito futuro para a região. 
32 InterAção

O problema reside nas embarcações oriundas de países que não fazem parte da CCAMLR. Pelo regime da UNCLOS, em alto-mar, as embarcações respondem apenas ao país onde se encontram registradas. Neste caso específico, a abordagem não pode ser realizada pelo inspetor da CCAMLR ao menos que a embarcação coopere voluntariamente, na recusa, limita-se a notificar o país de registro para realizar alguma providência. É comum que estes barcos utilizem as chamadas "bandeiras de conveniência", registro em países de baixa capacidade estatal que são coniventes com a pesca INN.

Outra discussão que precisa ser feita diz respeito à viabilidade material de manter operações de patrulhamento e inspeção por membros da CCAMLR. Dois requisitos são fundamentais para esta tarefa: possuir embarcações capazes de suportar o rigor do clima frio antártico e a capacidade de projeção para realizar operações na região, o que pode significar ter um porto de origem ou de apoio próximo ao território antártico. Um país que não possui condições econômicas ou operacionais de projetar a sua marinha ou guarda costeira para navegar em mares antárticos ou de regiões adjacentes não poderá colaborar com essa iniciativa. Sendo assim, existe uma tendência natural de delegar a tarefa de patrulhamento e inspeção da pesca INN sob o mandato da CCAMLR aos sete reivindicantes territoriais da Antártida que, via de regra, têm atuado regularmente na repressão da pesca INN na região (HAWARD, 2012, p. 232). Isto ocorre justamente por esses países serem os únicos a manterem forças marítimas em proximidade da região com o objetivo de zelar pelas suas pretensões territoriais e pela proteção das ZEEs de suas ilhas subantárticas. Neste contexto, destacam-se as capacidades de projeção marítima na região do Reino Unido, França, Austrália e Nova Zelândia, como pode ser observado no Quadro 2. Devido a crescente presença militar (ou paramilitar) destes países no Oceano Austral é preciso cogitar se existe um processo genuíno de securitização 
ambiental da região ou se, na realidade, trata-se apenas de uma militarização de um interesse puramente econômico pelos recursos marinhos existentes.

Quadro 2. Capacidade de Projeção de Força Marítima no Oceano Austral

\begin{tabular}{|c|c|c|c|c|c|}
\hline País & Embarcação & Fabricação & Porto mais próximo & Tripulação & Armamento \\
\hline $\begin{array}{c}\text { Reino } \\
\text { Unido }\end{array}$ & $\begin{array}{c}\text { HMS } \\
\text { Protector } \\
\text { (A173) }\end{array}$ & 2001 & $\begin{array}{c}\text { Falklands } \\
\text { (Atlântico Sul) }\end{array}$ & 88 & $\begin{array}{c}6 \text { metralhadoras } \\
\text { heliporto }\end{array}$ \\
\hline França & Nivôse (F732) & 1990 & $\begin{array}{c}\text { Ilha de Réunion } \\
\text { (Índico Sul) }\end{array}$ & 100 & $\begin{array}{c}3 \text { metralhadoras } \\
\text { 2 lança-mísseis } \\
\text { heliporto }\end{array}$ \\
\hline Austrália & $\begin{array}{c}\text { ABFC Ocean } \\
\text { Shield }\end{array}$ & 2010 & Sidney (Austrália) & 78 & $\begin{array}{c}3 \text { metralhadoras } \\
2 \text { lança-mísseis } \\
\text { heliporto }\end{array}$ \\
\hline \multirow{2}{*}{$\begin{array}{c}\text { Nova } \\
\text { Zelândia }\end{array}$} & $\begin{array}{c}\text { HMNZS } \\
\text { Otago (P148) }\end{array}$ & $\begin{array}{c}\text { HMNZS } \\
\text { Wellington } \\
\text { (P55) }\end{array}$ & 2005 & $\begin{array}{c}\text { Dunedingorto } \\
\text { Zelândia) }\end{array}$ \\
\hline
\end{tabular}

Quadro elaborado pelo autor, com base em Bush (2014), France (2018), Australia (2018) e New Zealand (2018).

A projeção de força destas nações no Oceano Austral já está gerando resultados. Em 2001, a South Tomi, de bandeira de Togo, foi interceptada por um barco do controle aduaneiro australiano sob a suspeita de pesca INN em território de ZEE da Austrália (Ilha Heard) e território antártico. Após 14 dias de perseguição, a embarcação acabou sendo capturada pela marinha da África do Sul, respondendo a solicitação da marinha australiana. Em 2003, em circunstâncias similares foi interceptado o Viarsa I, barco com bandeira do Uruguai. Após três semanas de perseguição, a embarcação foi abordada pela marinha australiana com auxílio de sul-africanos e britânicos (ROTHWELL, 2012, p. 141-143). Em 2015, foi a vez da marinha neozelandesa identificar dois barcos registrados na Guiné Equatorial como praticantes de pesca INN na região antártica e possivelmente em ZEE da Austrália. A marinha optou por pedir 
34 InterAção

autorização do governo da Guiné Equatorial antes de abordar, tendo sido concedido o pedido.

Outro foco de tensão securitária tem sido a atividade baleeira por embarcações japonesas no Oceano Austral, apesar da proibição. O Japão, país de tradicional consumo de carne de baleia, tem mascarado suas atividades exploratórias como sendo científicas (BEDELL, 2015, p. 03-05). Organizações ambientalistas (como o Sea Shepard) têm tentado impedir estas atividades, porém notícias apontam que os navios japoneses têm revidado utilizando armamento militar, granadas de concussão e armas acústicas. A pesca da baleira japonesa desencadeou uma ação na Corte Internacional de Justiça proposta por Austrália, que decidiu que não se tratava de atividade científica, constituindo-se violação do Direito Internacional aplicado à matéria.

As novas dinâmicas de securitização do Oceano Austral estão estimulando novas inciativas de cooperação, para além da CCAMLR, em dois exemplos paradigmáticos de natureza bilateral. A primeira diz respeito à Argentina e o Chile, que criaram em 1998 a "Patrulha Naval Combinada". Tratase de operação anual realizada durante o verão antártico, com a participação das duas marinhas, e dirigida ao patrulhamento de áreas próximas aos territórios antárticos de ambas as nações (DODDS, 2012, p, 110-112).

A outra iniciativa envolve Austrália e França, que assinaram acordos bilaterais (em 2003 e 2007) sobre a cooperação de ambas as marinhas no patrulhamento de suas ZEEs subantárticas e aplicação do law enforcement sobre as atividades de pesca INN (ROTHWELL, 2012, p. 142-143). Neste caso, o navio de patrulha recebe a bordo um oficial estrangeiro, responsável por autorizar ou desautorizar uma possível medida de força capaz de violar o seu Direito ou jurisdição nacional. Não se trata propriamente de uma inovação, visto que esse modelo (chamado de shiprider agreement) tem sido utilizado pelos EUA em 
tratados bilaterais envolvendo o controle de tráfico de drogas por via marítima na região do Caribe, em que navios norte-americanos patrulham com oficiais de países caribenhos a bordo (GUILFOYLE, 2009, p. 89).

\section{CONSIDERAÇÕES FINAIS}

Com os estoques pesqueiros ao redor do mundo à beira do colapso, com consequências ambientais, econômicas e sociais imensuráveis, as possibilidades de proliferação da pesca INN (ilegal, não declarada ou não regulamentada) passaram a ser acompanhadas com grande atenção pela comunidade internacional. A partir da pesquisa é possível observar o desencadeamento de um processo de securitização do tema, que passou a ser tratado como uma ameaça de segurança.

Entende-se que a definição de uma ameaça é uma prática autorreferencial e socialmente constituída, materializada por meio de um ato de fala e aceitação por uma respectiva audiência. Neste contexto, a securitização da pesca INN pode

ser comprovada por meio da pesquisa realizada nos planos nacionais de segurança e estratégia marítima consultados (dos Estados Unidos, Reino Unido, Espanha, França, Índia e União Europeia), que fazem diversas referências às práticas danosas destas atividades pesqueiras. Levando em consideração que se trata de documentos oficiais de países de relevância no cenário internacional, capazes de influenciar as estratégias de outros atores, entende-se que a hipótese de securitização encontra-se plenamente configurada. O problema é classificado como uma ameaça à segurança ambiental, econômica e alimentar, além de possuir laços com o crime organizado transnacional. 
36 InterAção

Como se desenvolve no mar, ambiente físico vasto e inóspito, a pesca INN enquanto problema de segurança necessita de uma estratégia de enfrentamento diferenciada. Neste cenário, a cooperação internacional e o Direito Internacional desempenham um papel importante. Atualmente, entende-se que a segurança marítima é muito complexa e difusa para o controle unilateral. Assim, as forças marítimas nacionais são compelidas a adotarem uma postura colaborativa com seus congêneres.

Direito e segurança marítima têm se tornado temas indissociáveis, visto que o Direito Internacional exerce a função de estabilizar expectativas e dirimir conflitos entre potências navais, por meio do estímulo à cooperação internacional no enfrentamento de ameaças comuns. Neste ponto, a UNCLOS é um dos instrumentos mais importantes, pois suas normas, adotadas amplamente pela comunidade internacional, impactam na segurança marítima e na regulação da pesca internacional. Destacam-se o estabelecimento de um dever geral de conservação dos recursos marinhos e a criação das zonas econômicas exclusivas.

Por se tratar de um território sem população nativa e longe da jurisdição dos Estados soberanos, o Oceano Austral é particularmente vulnerável à pesca INN. Existem indícios de uma possível expansão da pesca nessa região, o que pode ocasionar também o deslocamento das possíveis dinâmicas de segurança. A disputa pelas prováveis riquezas da região faz parte da história de exploração do Continente Antártico. Uma escalada de conflitos só não ocorreu por conta da formação de um regime internacional (o Sistema do Tratado da Antártida) que foi capaz de suspender as pretensões territoriais, promover a colaboração científica, limitar a presença militar e estabelecer o uso sustentável e racional dos recursos naturais. Neste contexto, as dinâmicas de segurança marítima no Oceano Austral submetem-se ao framework jurídico do Sistema do Tratado da Antártida (além das regras gerais da UNCLOS). 
A CCAMLR, constituída na forma de uma organização regional de pesca, é o principal instrumento responsável por coordenar a cooperação internacional no combate à pesca INN e na promoção da conservação do ecossistema marinho. As medidas adotadas pela CCAMLR, que incluem o monitoramento de entrada e saída das zonas de pesca, verificação dos registros e inspeções em embarcações dos Estados-membros, são medidas salutares para o enfrentamento do problema.

Não se pode olvidar, contudo, as limitações de seu alcance, uma vez que não se aplicam às embarcações de países que não fazem parte deste regime. $\mathrm{A}$ fiscalização depende inteiramente das forças marítimas nacionais, que agiram de acordo com os parâmetros impostos pela CCAMLR e UNCLOS. Os modelos de "guarda-costeira", em que utiliza como estratégia o emprego de força não letal, e de "marinha pós-moderna", em que se adota uma postura colaborativa com as instituições navais estrangeiras, parecem ser ideais para o contexto do Oceano Austral. Nem todos os Estados-membros da CCAMLR terão a capacidade necessária para conduzir atividades de patrulhamento, de modo que essa atribuição acaba recaindo para os países que dispõem recursos necessários, possivelmente aqueles que detêm soberania nas ilhas subantárticas e interesses político-econômicos na região. Neste cenário, destacam-se o Reino Unido, França, Austrália e Nova Zelândia, que possuem capacidade de projeção de força necessária para estas operações. De modo geral, apesar das possibilidades de escalada de securitização e consequentes conflitos, as dinâmicas encontradas no Oceano Austral, pelo menos no que tange à exploração de seus recursos pesqueiros, revelaram-se profícuas para o florescimento de iniciativas de cooperação internacional. 


\section{REFERÊNCIAS}

ABDEL-MOTAAL, Doaa. Antarctica: The Battle for the Seventh Continent.

AGNEW, David J. Estimating the Worldwide Extent of Ilegal Fishing. PLOSONE. Atlanta, 2009.

ANTARTIC AND SOUTHERN OCEAN COALITION. Krill Conservation. Disponível em: <https://www.asoc.org/advocacy/krill-conservation>. Acesso em: 15 fev. 2018.

AUSTRALIA. Department of Home Affairs - Australian Border Force Cutter Ocean Shield. Acesso em: <https:/ / www.homeaffairs.gov.au/australianborder-force-abf/protecting/maritime/cutter-abfc-oceanshield\#Southern\%20Ocean\%20operations>. Disponível em: 31 jul. 2018.

BATEMAN, Sam. Strategic Competition and Emerging Security Risks: Will Antarctica Remain Demilitarised? In: ROTHWELL, Donald R.; SCOTT, Karen N.; HEMMINGS, Alan D. The Search for Antarctic Security. In: ROTHWELL, Donald R.; SCOTT, Karen N.; HEMMINGS, Alan D (Org.). Antarctic Security in the Twenty-First Century: Legal and Policy Perspectives. Londres: Routledge, 2012, p. 116-134.

BECKMAN, Robert. The UN Convention on the Law of the Sea and the Maritime Disputes in the South China Sea. The American Journal of International Law, v. 107, p. 142-163, 2003.

BUEGER, Christian; EDMUNDS, Timothy. Beyond Seablindness: A New Agenda for Maritime Security Studies. International Affairs, v. 93, n. 6, p. 1293 1311, 2017.

BUSH, Steve. British Warship and Auxiliaries. London: Maritime Books, 2014. BUZAN, Barry; WAEVER, Ole; WILDE, Jaap de. Security: A New Framework for Analysis. London: Lynne Rienner, 1998.

CCAMLR. Ilegal, Unreported and Unregulated Fishing. Disponível em: <https:// www.ccamlr.org/en/compliance/illegal-unreported-andunregulated-iuu-fishing>. Acesso em: 31 mar. 2018.

CCAMLR. Krill Fishery Report 2017. Disponível em: <https:/ / www.ccamlr.org/en/system/files/00\%20KRI48\%202017.pdf>. Acesso em: 31 mar. 2018. 
CNN. Argentina Sinks Chinese Vessel. Disponível em:

<https://edition.cnn.com/2016/03/15/americas/argentina-chinese-fishingvessel/index.html.>.Acesso em: 31 jul. 2018.

DODDS, Klaus. The Antarctic Peninsula: Territory, Sovereignty Watch and The "Antarctic Problem". In: ROTHWELL, Donald R.; SCOTT, Karen N.;

HEMMINGS, Alan D. The Search for Antarctic Security. In: ROTHWELL, Donald R.; SCOTT, Karen N.; HEMMINGS, Alan D (Org.). Antarctic Security in the Twenty-First Century: Legal and Policy Perspectives. Londres: Routledge, 2012, p. 95-115.

DODDS, Klaus; HEMMINGS, Alan D. Britain and the British Antarctic Territory in the Wider Geopolitics of the Antarctic and the Southern Ocean. International Affairs, v. 89, n. 06, p. 1429-1444, 2013.

ESPAÑA. National Maritime Security Strategy. Disponível em: <http:/ / www.lamoncloa.gob.es/documents/20131333estrategiadeseguridadm artima_ingls.pdf $>$. Acesso em: 31 jul. 2018.

EUROPEAN UNION. European Union Maritime Security Strategy. Disponível em: <https:/ / ec.europa.eu/maritimeaffairs/policy/maritime-security_en>. Acesso em: 31 jul. 2018.

FABRA, Adriana; GASCÓN, Virginia. The Convention on the Conservation of Antarctic Marine Living Resources (CCAMLR) and the Ecosystem Approach. The International Journal of Marine and Costal Law, v. 23, p. 567-598, 2008.

FERREIRA, Luciano Vaz. Direito Internacional da Guerra. Jundiaí: Paco Editoral, 2014.

FOOD AND AGRICULTURE ORGANIZATION OF THE UNITED NATIONS (FAO). The State of World Fisheries and Acquaculture: Opportunities and Challenges. Roma: FAO, 2014.

FOOD AND AGRICULTURE ORGANIZATION OF THE UNITED NATIONS (FAO). The State of World Fisheries and Acquaculture: Contributing to Food Security and Nutrition for All. Roma: FAO, 2016.

FOOD AND AGRICULTURE ORGANIZATION OF THE UNITED NATIONS (FAO). World Fish Market at Glance. 2017. Disponível em: <http://www.fao.org/in-action/globefish/fishery-information/resourcedetail/en/c/338597/ >. Acesso em 31 mai. 2018.

FOSTER, Carline E. Antarctic Resources and Human Security. In: ROTHWELL, Donald R.; SCOTT, Karen N.; HEMMINGS, Alan D (Org.). Antarctic Security 
in the Twenty-First Century: Legal and Policy Perspectives. Londres: Routledge, 2012, p. 154-171.

FIGUEIREDO, E. L.. Os Estudos Estratégicos, a Defesa Nacional e a Segurança Internacional. In: Lessa, Renato. (Org.). Horizontes das Ciências Sociais no Brasil (Ciência Política). 1ed.São Paulo: Anpocs/Editora Barcarolla / Discurso Editorial/ICH, 2010, v. 1, p. 271-295.

FRANCE. Marine Nationale - Flóreal. Disponível em: $<$ https://www.defense.gouv.fr/marine/equipements/batiments-decombat/fregates/de-surveillance/floreal-f-730>. Acesso em: 31 jul. 2018.

FRANCE. Marine Nationale - Nivôse. Disponível em: <https://www.defense.gouv.fr/marine/equipements/batiments-decombat/fregates/de-surveillance/nivose-f-732>. Acesso em: 31 jul. 2018.

FRANCE. Disponível em:

<https://www.gouvernement.fr/sites/default/files/contenu/piecejointe/2016/01/strategie_nationale_de_surete_des_espaces_maritimes_en_nati onal_strategy_for_the_security_of_maritime_areas.pdf $>$. Acesso em: 31 jul. 2018 .

FULTON, Thomas Wemyss. The Sovereignty of the Sea. London:William Blackwood and Sons, 1911.

GUILFOYLE, Douglas. Shipping Interdiction and the Law of the Sea. Cambridge: Cambridge, 2009.

HAENLEIN, Cathy. Below the Surface: How Illegal, Unreported and Unregulated Fishing Threatens our Security. Londres: RUSI, 2011.

HAWARD, Marcus. Marine Resources Management, Security And Antartic Treaty System: Na Ongoing Agenda? In: ROTHWELL, Donald R.; SCOTT, Karen N.; HEMMINGS, Alan D (Org.). Antarctic Security in the Twenty-First Century: Legal and Policy Perspectives. Londres: Routledge, 2012, p. 216-237.

INDIA. Ensuring Secure Seas: Indian Maritime Security Strategy. Disponível em:

<https://www.indiannavy.nic.in/sites/default/files/Indian_Maritime_Securit y_Strategy_Document_25Jan16.pdf> . Acesso em: 31 jul. 2018.

KAWARAZUKA, Nozomi; BÉNÉ, Christophe. The potential role of small fish species in improving micronutrient deficiencies in developing countries: building evidence. Public Health Nutrition, v. 14, n. 11, p. 1927-1938, 2011. 
41 InterAção

KLEIN, Natalie. Maritime Security and the Law of the Sea. Oxford: Oxford University Press, 2011.

KRASKA, James; PEDROZO, Raul. International Maritime Security Law. Boston: Martinus Nijhoff Publishers, 2013.

KRASKA. James. Maritime Power and the Law of the Sea: Expeditionary Operations in World Politics. Oxford: Oxford University Press, 2011.

KRASNER, Stephen D. Structural Cases and Regime Consequences: Regimes as Intervening Variables. International Organization, Cambridge, v. 36, n. 2, p. 185-205, 1982.

MACK, John. The Sea: A Cultural History. Londres: Reaktion, 2011.

MATTHEW, Richard A. Global Environmental Change and Human Security. Boston: MIT, 2010.

MYERS, Norman. The Environmental Dimension to Security Issues.

Environmentalist, v. 6, n. 4, p. 251-257.

NATIONAL INTELLIGENCE COUNCIL. Global Implications of Ilegal, Unreported and Unregulated (IUU) Fishing. 2016. Disponível em:

<https://fas.org/irp/nic/fishing.pdf> Acesso em: 31 mai. 2018.

NEW ZEALAND. Royal New Zealand Navy - HMNZ Otago. Disponível em: <http:// navy.mil.nz/mtf/otago/>. Acesso em: 31 jul. 2018.

NEW ZEALAND. Royal New Zealand Navy - HMNZ Wellington. Disponível em: <http://navy.mil.nz/mtf/well/>. Acesso em: 31 jul. 2018.

PALMA, Mary Ann; TSAMENYI, Martin; EDESON, William. Promoting Sustainable Fisheries: The International Legal and Policy Framework to Combat Ilegal, Unreported and Unregulated Fishing. Leiden: Martinus Nijhoff, 2010.

PARIS, Roland. Human Security: Paradigm Shift or Hot Air? International Security, v. 26, n. 1, p. 87-102, 2001.

PAULY, Daniel; ZELLER, Dirk. Catch reconstructions reveal that global marine fisheries catches are higher than reported and declining. Nature

Communications, n. 7, fev. 2015.

ROTHWELL, Donald R.; SCOTT, Karen N.; HEMMINGS, Alan D. The Search for Antarctic Security. In: ROTHWELL, Donald R.; SCOTT, Karen N.; HEMMINGS, Alan D (Org.). Antarctic Security in the Twenty-First Century: Legal and Policy Perspectives. Londres: Routledge, 2012, p. 1-17. 
ROTHWELL, Donald R. Law Enforcement in Antarctica. In: ROTHWELL, Donald R.; SCOTT, Karen N.; HEMMINGS, Alan D. The Search for Antarctic Security. In: ROTHWELL, Donald R.; SCOTT, Karen N.; HEMMINGS, Alan D (Org.). Antarctic Security in the Twenty-First Century: Legal and Policy Perspectives. Londres: Routledge, 2012, p. 136-153.

ROTHWELL, Donald R.; STEPHENS, Tim. The International Law of the Sea. Oxford: Bloomsburry, 2016.

SANDS, Philippe. Principles of International Environmental Law. 2 ed. Cambridge: Cambridge University Press, 2003.

SHAVER, Amanda; YOZELL, Sally. Casting a Wider Net: The Security Implications of Ilegal, Unreported and Unregulated Fishing. Washington: Stimson Center, 2018.

SPELLER, Ian. Understading Naval Warfare. New York: Routledge, 2014.

STEINBERG, Philip E. The Social Constructo f Ocean. Cambridge: Cambridge University Press, 2001.

TILL, Geoffrey. Seapower: A Guide for the Twenty-First Century. New York: Routledge, 2014.

TILL. Geoffrey. The Changing Dynamics of Seapower and Concepts of Battle. In: BEKKEVOLD, Jo Inge; TILL, Geoffrey (Org.). International Order at Sea: How it is Challenged, How it is Maintained. Londres: Palgrave Macmillian, 2016, p. 177-198.

ULLMAN, Richard H. Redefining Security. International Security, v. 8, n. 1, p. 129-153, 1983.

UNITED NATIONS DEVELOPMENT PROGRAMEE (UNDP). Human Development Report 1994. Oxford: Oxford University Press, 1994.

UNITED KINGDOM. UK National Strategy for Maritime Security. Disponível em:

<https:/ / assets.publishing.service.gov.uk/government/uploads/system/uplo ads/attachment_data/file/322813/20140623-40221_national-maritime-strat-

Cm_8829_accessible.pdf>. Acesso em: 31 jul. 2018.

UNITED STATES OF AMERICA. 1990. Antarctic Treaty Handbook:

Conservation of Antarctic Seals. Disponível em:

<https://www.state.gov/documents/organization/15280.pdf>. Acesso em: 31 mar. 2018. 
43 InterAção

UNITED STATES OF AMERICA. The National Strategy for Maritime Security. Disponível em:

<https://www.state.gov/documents/organization/255380.pdf> . Acesso em 31 mai. 2018.

WEAVER, Ole. Securitization and Desecuritization. In: LIPSCHUTZ, Ronnie. On Security: Columbia University Press: New York, 1995, p. 46-86.

WWF. Fishing problems: Destructive fishing practices. Disponível em: <http://wwf.panda.org/our_work/oceans/problems/destructive_fishing/> Acesso em: 31 mai. 2018. 